\title{
A study on Structural Aspects and Biological Activity of (E)-N'- [2-Hydroxybenzylidene]benzohydrazide and its Metal Complexes
}

\author{
A.Padmaja ${ }^{1}$, K.Laxmi ${ }^{2}{ }^{3}$ Ranjit Reddy Palreddy and Ch.Sarala Devi * \\ ${ }^{1}$ Department Of Chemistry University College of Science, Saifabad, Osmania University, Hyderabad-500 004, \\ India \\ ${ }^{2}$ Department Of Chemistry, Chaitanya Bharati Institute Of Technology, Gandipet, Hyderabad -500 075, India \\ ${ }^{3 *}$ Department of Chemistry, University College of Science, Osmania University, Hyderabad - 500007, India
}

\begin{abstract}
The spectroanalytical studies of $V O(I I), M n(I I), C o(I I), N i(I I)$ and $\mathrm{Cu}(I I)$ complexes with the title compound (E)-N'-[2-Hydroxybenzylidene]benzohydrazide, as wellas antifungal and antibacterial activity of $\mathrm{Cu}(I I)-H B B H$ complex were carried out. The complexes were characterizedby elemental analysis, $I R, N M R$, mass,ESR and TGA \& DTA. The mode of bonding in these complexes has been suggested on the basis of analytical and spectroscopic data. The ligand coordinates to the central metal ion through oxygen of enolic form of carboxy hydrazone, phenolic oxygen and azomethine nitrogen atoms in $\mathrm{VO}(\mathrm{II}), \mathrm{Mn}(\mathrm{II})$, and $\mathrm{Cu}(\mathrm{II})$ complexes through the dissociation of two protons. While in Co(II) and Ni(II) complexes the dissociation of only phenolic proton is observed and hence the donor sites are oxygen of phenolic group, amide carbonyl oxygen and imine nitrogen. The $\mathrm{Cu}(\mathrm{II})$ complex exhibits lethal effect on gram negative bacteria Escherichia coli and fungal strain Candida albicans. It has also been observed that concentration of compounds play a vital role in the degree of inhibition.
\end{abstract}

Key words: (E)-N'-[2-Hydroxybenzylidene]benzohydrazide(HBBH), VO(II), $\mathrm{Mn}(\mathrm{II}), \mathrm{Co}(\mathrm{II}), \mathrm{Ni}(\mathrm{II})$ and $\mathrm{Cu}(\mathrm{II})$ complex, Biological activity

\section{Introduction}

There has been considerable interest in the development of novel compounds with antiinflamatory, analgesic, antimicrobial, antitumor, antiviral activities. Hydrazones with various biological activity possessing an azomethine $-\mathrm{NHN}=\mathrm{CH}$ - proton constitute an important class of compounds for new drug development. Also these ligands and their metal complexes play an important role in the development of coordination chemistry and are good complexing agents. A number of complexes have been reported with amide group ligands, which exhibit diverse coordinating behaviour with different metal ions ${ }^{1-2}$. The amide group offers two potential binding atoms, the oxygen and nitrogen, for complexation with metal ions. The copper (II) complex of 5bromosalicylaldimine exhibits antibacterial activity and benzoyl hydrazones of salicylaldehyde exhibits antibacterial, antifungal, antimicrobial activities. The 2-hydroxy-4-chloro benzoyl hydrazone has antimicrobial activity ${ }^{3}$. Therefore many researchers have synthesized these compounds as target structures and elevated their biological activities. These observations have been guiding for the development of new hydrazones that possess varied biological activities.

Keeping in view the various biological activities, synthesis and characterization of some transition metal complexes with 2-hydroxy benzilydene benzohydrazide (HBBH), and biological activity of its copper complex have been discussed in the present investigation.

\section{Experimental Section}

I.R spectra were recorded on a Perkin-Elmer 435 Spectrophotometer. ${ }^{1} \mathrm{H}$ NMR were recorded in $\mathrm{CDCl}_{3} / \mathrm{DMSO}_{6}$ on a Bruker WH (270 MHZ) spectrometer, mass spectra were recorded on Micro Mass V.G70-70H spectrometer operating at $70 \mathrm{eV}$ using direct inlet system. Thermal behavior of complexes studied by thermal gravimetrical analysis (TGA) and differential thermal analysis (DTA) techniques were recorded on Mettler Toledo TGA/SDTA in the temperature range of $0-1000^{\circ} \mathrm{C}$ in nitrogen atmosphere at a heating rate of $20^{\circ} \mathrm{C} / \mathrm{min}$.

\subsection{Materials}

All the chemicals and solvents were of Analar grade. Solvents such as water, ethanol and methanol were purified before use by following standard procedures ${ }^{4}$.Nutrient broth (NB), Nutrent Agar (NA), Sabouraud dextrose agar (SDA), Sabouraud dextrose broth (SDB), Peptone water and antibiotics Ciprofloxacin (Bacteria), Ketaconazole (Fungi) were from Hi-media laboratories. DMSO was used from E.Merck. 


\subsection{Synthesis of ligand}

Ligand HBBH is synthesized by the reported procedure ${ }^{5}$.

1.3 Synthesis of metal complexes

The metal complexes of $\mathrm{Cu}$ (II), $\mathrm{Ni}$ (II), $\mathrm{Co}$ (II) and $\mathrm{Mn}$ (II) were prepared by mixing ethanolic solution of the ligand (E)-N'-[2-hydroxy benzylidene] benzohydrazide (HBBH) and corresponding metal chloride solution in 1:2 molar ratio. The resulting mixture was refluxed on water bath for 10-12 hours. The $\mathrm{pH}$ of the solution for complexation was maintained by adding few drops of dilute methanolic ammonium hydroxide solution $(\mathrm{pH} 4-7)$. The precipitated complexes are then recrystalized in ethanol. The resulting complexes are washed with petroleum ether and dried under pressure over anhydrous $\mathrm{CaCl}_{2}$ in a dessicator.

The metal complex of vanadium is synthesized by adopting different method.To an equal volume of water concentrated sulphuric acid, solution of vanadium pentoxide dissolved in ethanol is added with constant stirring and the resulting mixture is boiled until the colour changes from green to blue. As a result the solid precipitate separated is collected from the cooled mixture by filtration and HBBH ligand (dissolved in ethanol) is added to the filtrate. The acid reaction mixture is neutralized by careful addition of $10 \%$ sodium carbonate solution with stirring. The resulting compound is separated by filtration on the Buchner funnel and is allowed to dry in a dessicator.

All the complexes are quite stable to air and moisture, the physical state of all complexes is amorphous and all are coloured, with good solubility in DMSO.

\subsection{Infrared Spectra}

\section{Results and Discussion}

A comparative study of the IR spectrum of ligand with that of the metal complexes showed disappearance of $v_{\mathrm{OH}}$ absorption band which was observed as broad band centered at $3366 \mathrm{~cm}^{-1}$. The appearance of this band as broad band around $3431 \mathrm{~cm}^{-1}$ in the spectra of complexes is assigned to associated water molecule. A strong band at $1621 \mathrm{~cm}^{-1}$ due to $v_{(\mathrm{C}=0)}$ amide group and band at $1606 \mathrm{~cm}^{-1}$ due to $v_{(\mathrm{C}=\mathrm{N})}$ azomethine in the ligand HBBH has shifted down to 1605 and to 1570 in the spectra of VO (II), Mn (II), $\mathrm{Co}$ (II), Ni (II) and $\mathrm{Cu}$ (II) metal complexes "Figs. 1, 2,3,4 \& 5". This suggests the involvement of the azomethine group and amide group in coordination with the metal ${ }^{6-8}$. Another important ligand band at $1368 \mathrm{~cm}^{-1}$ due to phenolic-OH deformation is found to be absent in complexes. This indicates the deprotonation of phenolic-OH on coordination with metal ions ${ }^{9-10}$. A band at $1272 \mathrm{~cm}^{-1}$ in ligand spectrum due to C-O shifts to higher side in complexes. This substantiates the aforementioned observations ${ }^{11-12}$. A medium intensity band at $758 \mathrm{~cm}^{-1} \pm 4 \mathrm{~cm}^{-1}$ in all the metal complexes is assignable to rocking mode due to coordinated water molecule. Some new bands of weaker intensity at $530 \pm 20 \mathrm{~cm}^{-1}$ and $462 \mathrm{~cm}^{-1}$ are due to $v_{(\mathrm{M}-\mathrm{O})}$ and $v_{(\mathrm{M}-\mathrm{N})}$ bonding.

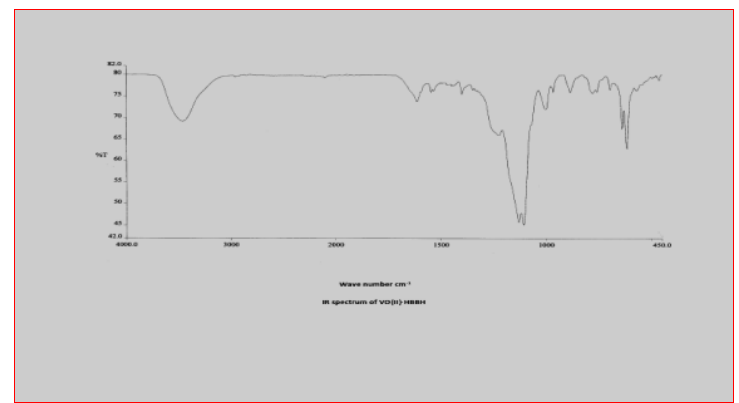

Fig.1 IR spectrum of VO (II)-HBBH

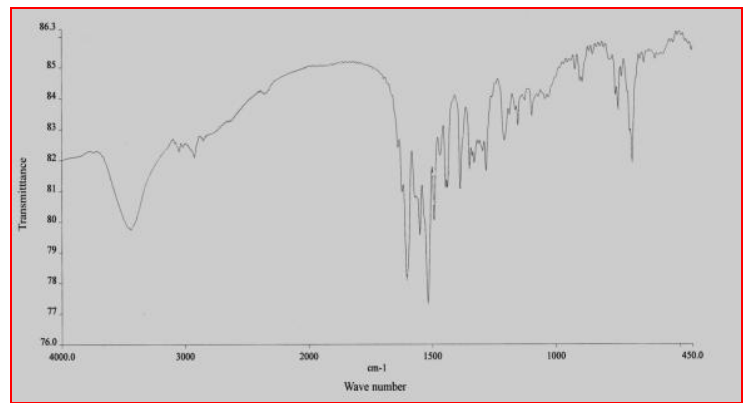

Fig.3 IR spectrum of Co (II)-HBBH

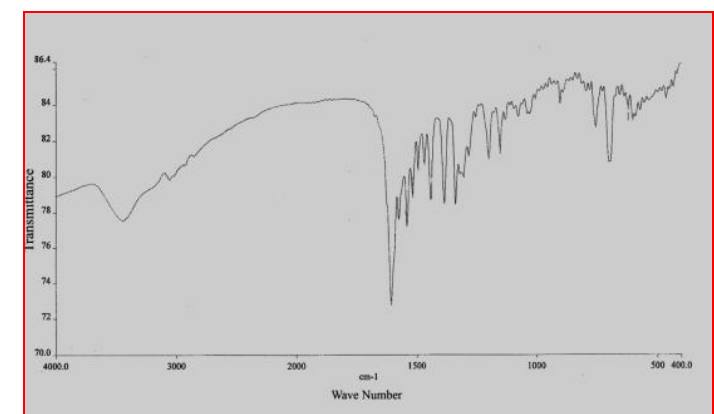

Fig.2 IR spectrum of Mn (II)-HBBH

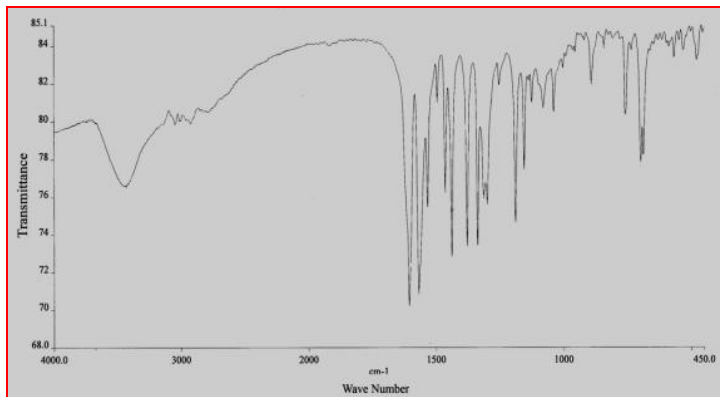

Fig.4 IR spectrum of Ni (II)-HBBH 


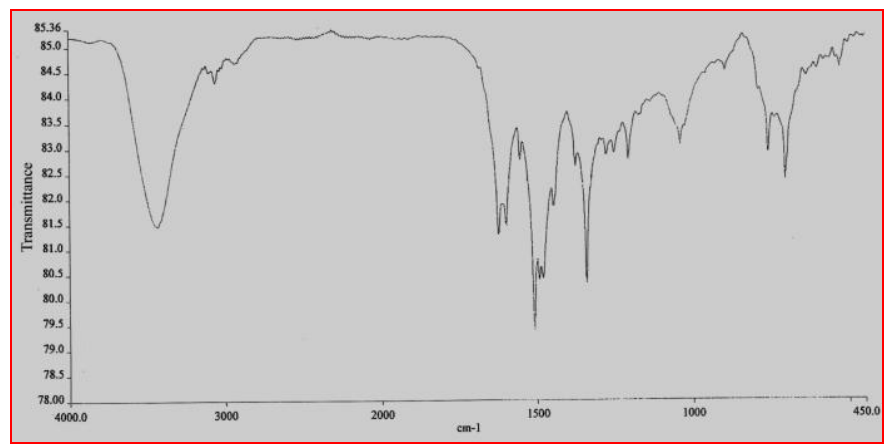

Fig.5 IR spectrum of $\mathrm{Cu}$ (II)-HBBH

\section{$1.5{ }^{1} \mathrm{H}-\mathrm{NMR}$ spectrum of $\mathrm{VO}(\mathrm{II})$-HBBH complex}

On comparison with the ligand spectrum of $\mathrm{HBBH}^{5}$, the ${ }^{1} \mathrm{H}-\mathrm{NMR}$ spectrum of vanadium complex exhibits a peak around $\delta 8.9 \mathrm{ppm}$. The appearance of this peak is assigned to azomethine proton which is in downfield region due to deshielding of the proton. This suggests the involvement of azomethine group in coordination with the metal ion. The disappearance of chemical shift due to phenolic proton and amide proton in the proton NMR spectrum of the vanadyl complex further gives evidence for the involvement of phenolic oxygen and carbonyl oxygen in coordination with the metal ion. The complex spectrum retains the aromatic protons appearing around the region $\delta 6-7.5 \mathrm{ppm}$ as in the ligand spectrum. Thus the above information gives evidence for the formation of metal complex involving phenolic-O, carbonyl-O and azomethine nitrogen in coordination with the vanadyl ion "Fig6" .

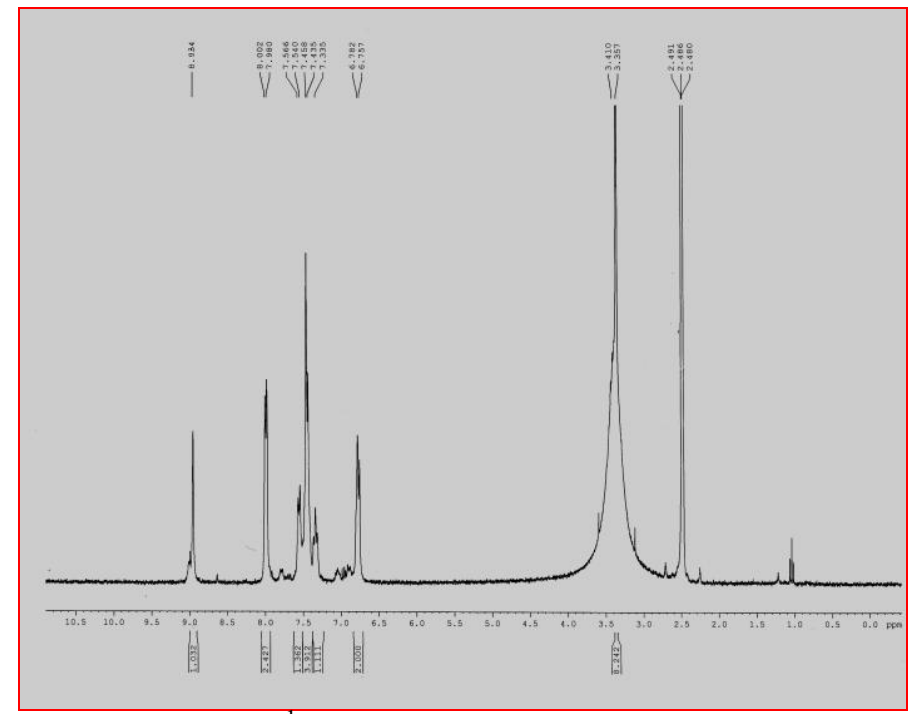

Fig.6 $\quad{ }^{\mathrm{I}}$ NMR spectrum of VO (II)-HBBH

\subsection{Mass Spectra}

The mass spectra of all metal complexes shows a fragment ion peak at $\mathrm{m} / \mathrm{z} 241$, which is consistent with the expected protonated ion $(\mathrm{M}+\mathrm{H})^{+}$as observed in the ligand mass spectrum ${ }^{5}$. The molecular ion peak occurs at $\mathrm{m} / \mathrm{z}=293$ in the mass spectrum of $\mathrm{Mn}(\mathrm{II})-\mathrm{HBBH}$ complex "Fig.7". The mass spectrum of this complex also shows fragment ion of lower intensity at $\mathrm{m} / \mathrm{z}=294$ that corresponds to carbon isotope. The peak at $\mathrm{m} / \mathrm{z}=293$ gives inference about the existence of the metal complex in 1:1 ratio.

The mass spectrum of $\mathrm{Co}(\mathrm{II})-\mathrm{HBBH}$ "Fig.8" shows a molecular ion peak $(\mathrm{M})^{+}$at $\mathrm{m} / \mathrm{z}=537$ suggesting the complex to be dimeric. Analysis by mass spectroscopy gave the molecular ion $\left[\mathrm{M}^{+}\right]$ peak of complex Ni(II)-HBBH "Fig.9" at desired position $\mathrm{m} / \mathrm{z}=534$ indicating dimeric nature of metal complex. The mass spectrum of $\mathrm{Cu}(\mathrm{II})-\mathrm{HBBH}$ complex "Fig.10" also contains ions at $\mathrm{m} / \mathrm{z} \mathrm{263}$, some 23 mass units higher than the ligand mass. These are identified as sodium adduct peaks . 


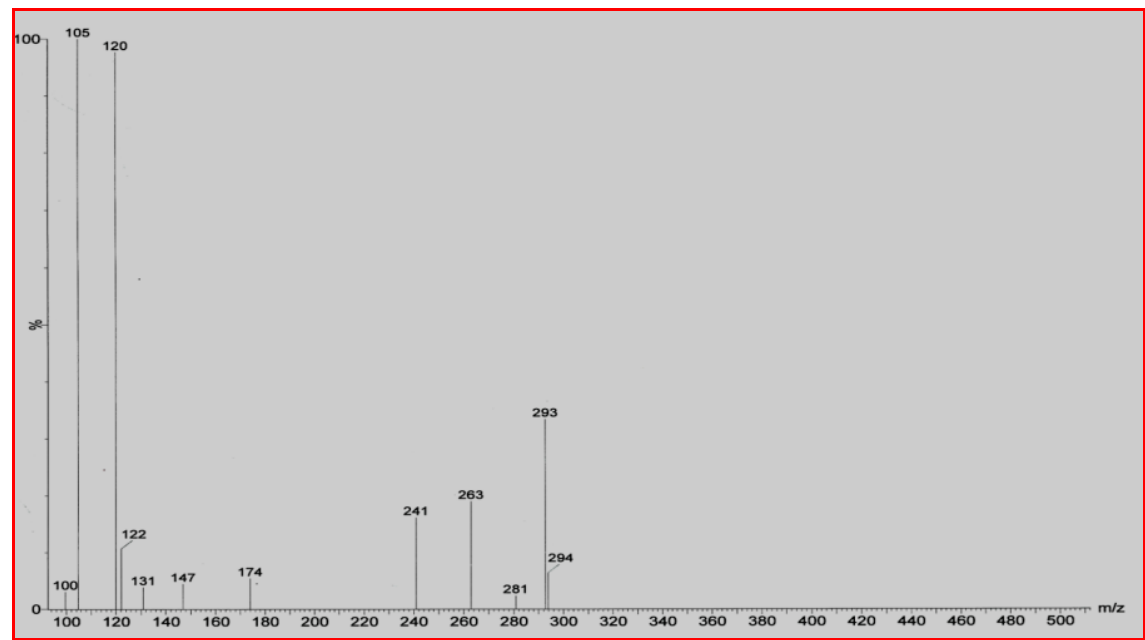

Fig.7 Mass spectrum of Mn (II) - HBBH

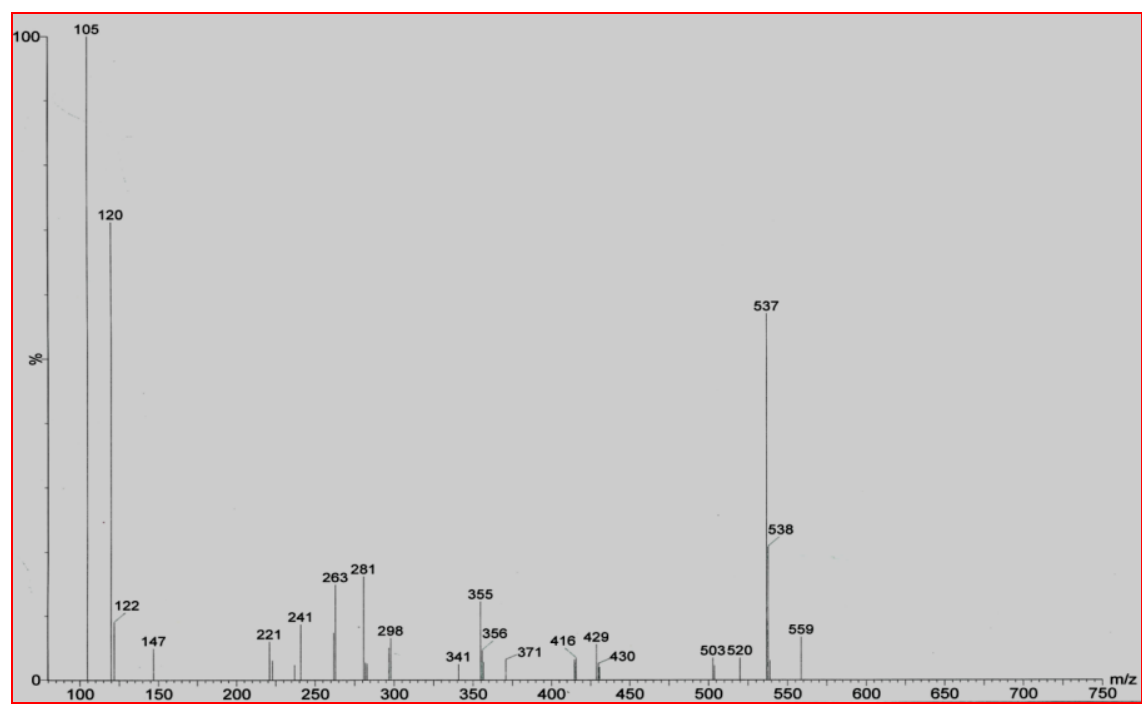

Fig.8 Mass spectrum of $\mathrm{Co}$ (II) $-\mathrm{HBBH}$

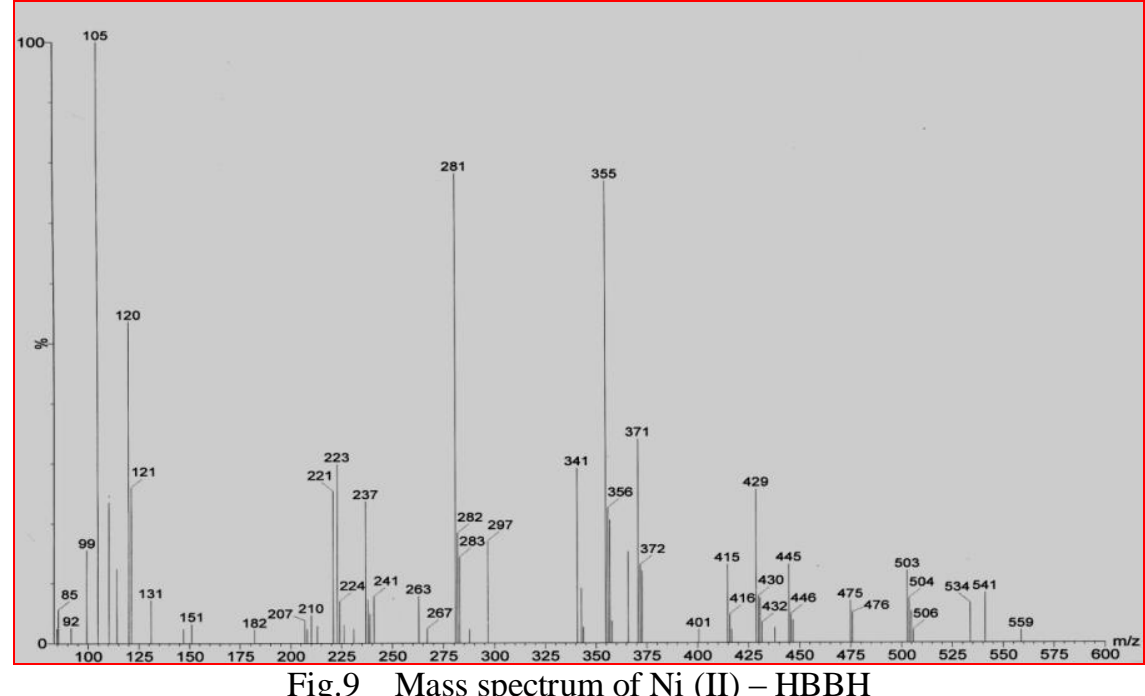

Fig.9 Mass spectrum of Ni (II) - HBBH 


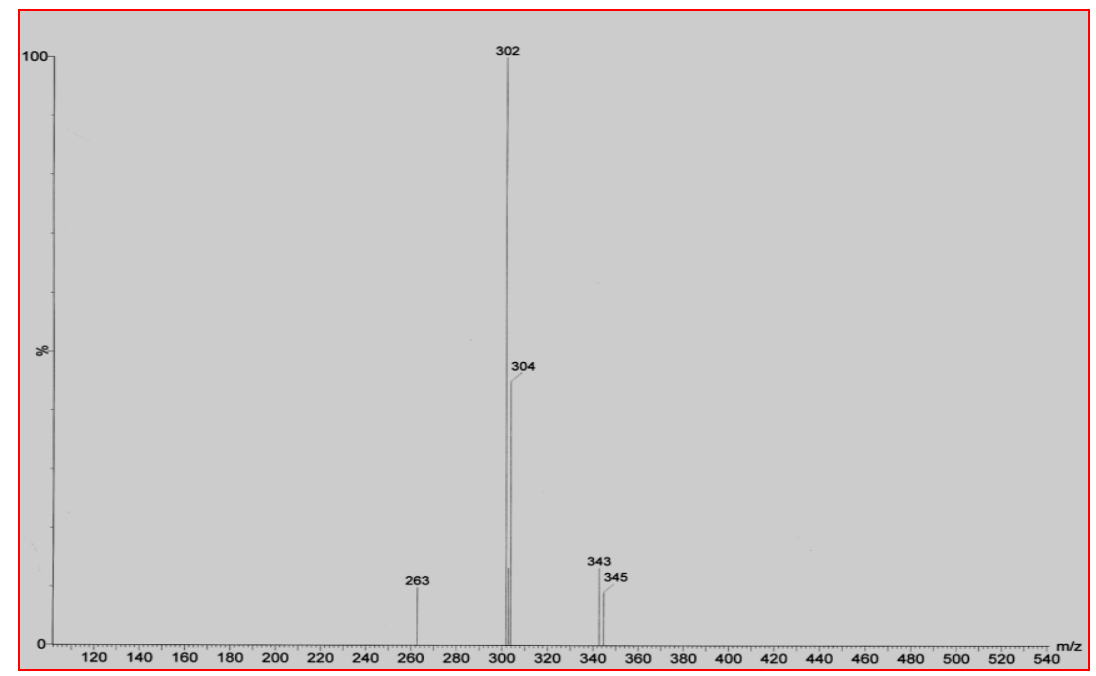

Fig.10 Mass spectrum of $\mathrm{Cu}$ (II) $-\mathrm{HBBH}$

\subsection{Electron Spin Resonance Spectra}

The ESR spectra of metal complexes were recorded in liquid nitrogen at room temperature.

The ESR spectra of the vanadyl (II) complex "Fig.11" shows a typical eight-line pattern. This eight-line pattern indicates that the unpaired electron interacts with the nuclear spin of single vanadium V $(I=7 / 2)^{13-14}$. The result is seen as hyperfine splitting of the ${ }^{51} \mathrm{~V}$ nucleus and the values suggests the complex to be square pyramidal.

The spectrum of the Mn (II)-HBBH complex " Fig.12" at LNT shows a six fold splitting indicating symmetrical six coordination of the $\mathrm{Mn}$ (II) ion. In this spectrum the g values are isotropy with small anisotropy due to increasing magnitude of the applied magnetic field. The interaction of nuclear spin of copper with unpaired electrons is seen in the spectrum by a six fold $(2 \mathrm{I}+1)$ splitting. As the g values are isotropic the metal ion is in cubic environment.

The ESR spectrum of $\mathrm{Cu}(\mathrm{II})-\mathrm{HBBH}$ complex " Fig.13" shows four well resolved peaks in $\mathrm{g}_{\mathrm{\prime}}$ region indicating the monomeric form of complex due the hyperfine interactions. While in $g_{\perp}$ region the resolution is poor. The trend $g_{n}>g \perp$ for this complex indicates that unpaired electron is localized in the $d_{x}{ }^{2}-y_{y}{ }^{2}$ orbital of $\mathrm{Cu}$ (II) ion and is characteristic for the axial symmetry. These results suggests that $\mathrm{Cu}$ (II)-HBBH complex has tetragonal elongation along the $\mathrm{z}$-axis.

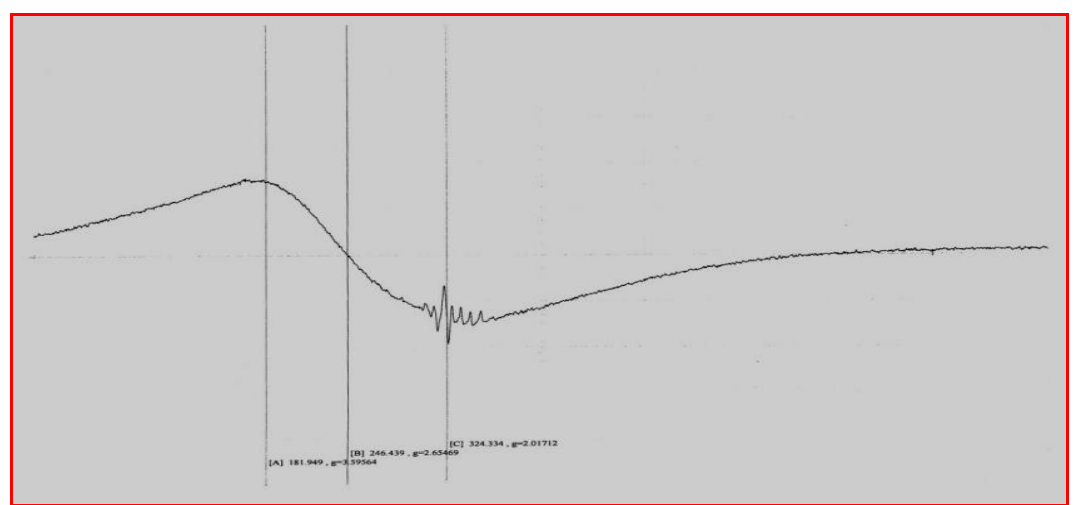

Fig.11 ESR of VO(II) $-\mathrm{HBBH}$ 


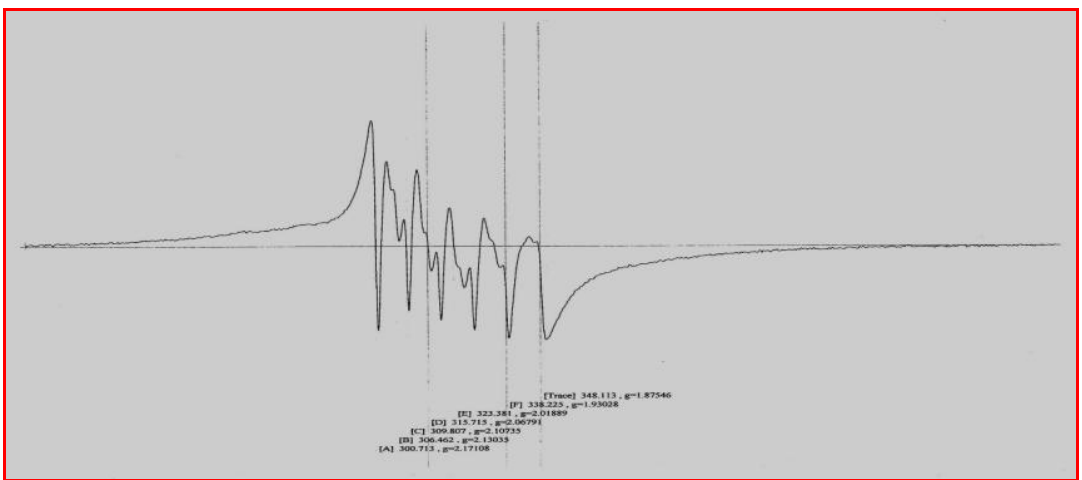

Fig.12 ESR of Mn(II)-HBBH

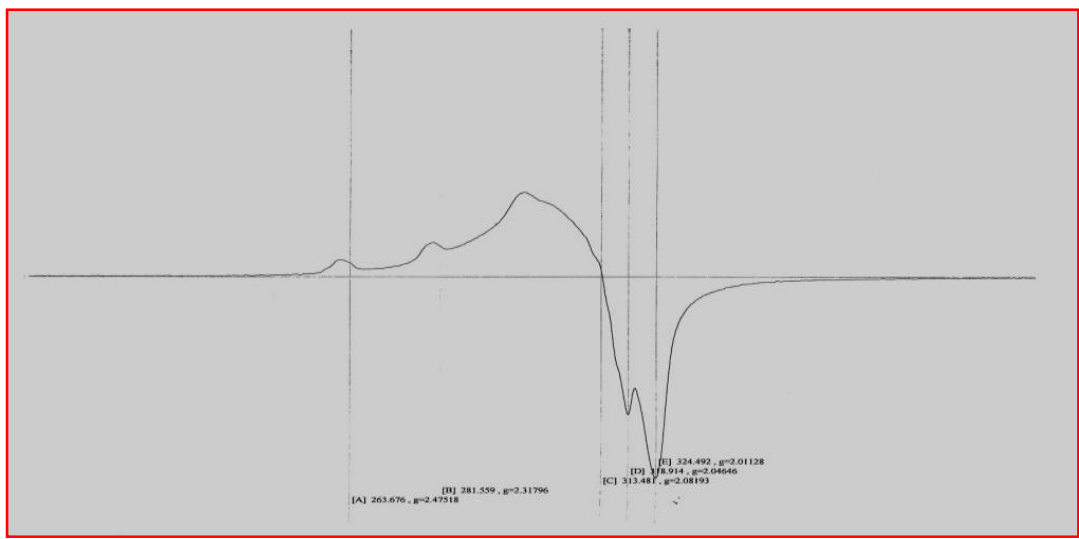

Fig.13 ESR of $\mathrm{Cu}(\mathrm{II})-\mathrm{HBBH}$

1.8 Thermal Studies of M (II) -HBBH complexes

Thermal gravimetrical analysis (TGA) and differential thermal analysis (DTA) of the complexes $\mathrm{VO}(\mathrm{II}), \mathrm{Mn}(\mathrm{II}), \mathrm{Co}(\mathrm{II}), \mathrm{Ni}(\mathrm{II})$ and $\mathrm{Cu}(\mathrm{II})-\mathrm{HBBH}$ complexes " Figs.14,15,16,17 \& 18 " shows a gradual weight loss in the temperature range $114^{\circ} \mathrm{C}$ to $200^{\circ} \mathrm{C}$ and an endothermic DTA peak in the region around $300^{\circ} \mathrm{C}$ in all the metal complexes indicates loss of coordinated water molecule. The second step of decomposition from $280^{\circ}$ $\mathrm{C}$ to $800^{\circ} \mathrm{C}$ in all the metal complexes corresponds to decomposition of ligand moiety. An exothermic peaks $\mathrm{t}_{\max }=600^{\circ} \mathrm{C}$ on DTA curve occurs for VO(II) - HBBH complex "Fig.14" during the second stage of decomposition. The mass of the final residue in all the metal complexes corresponds to stable metal ion or metal oxide.

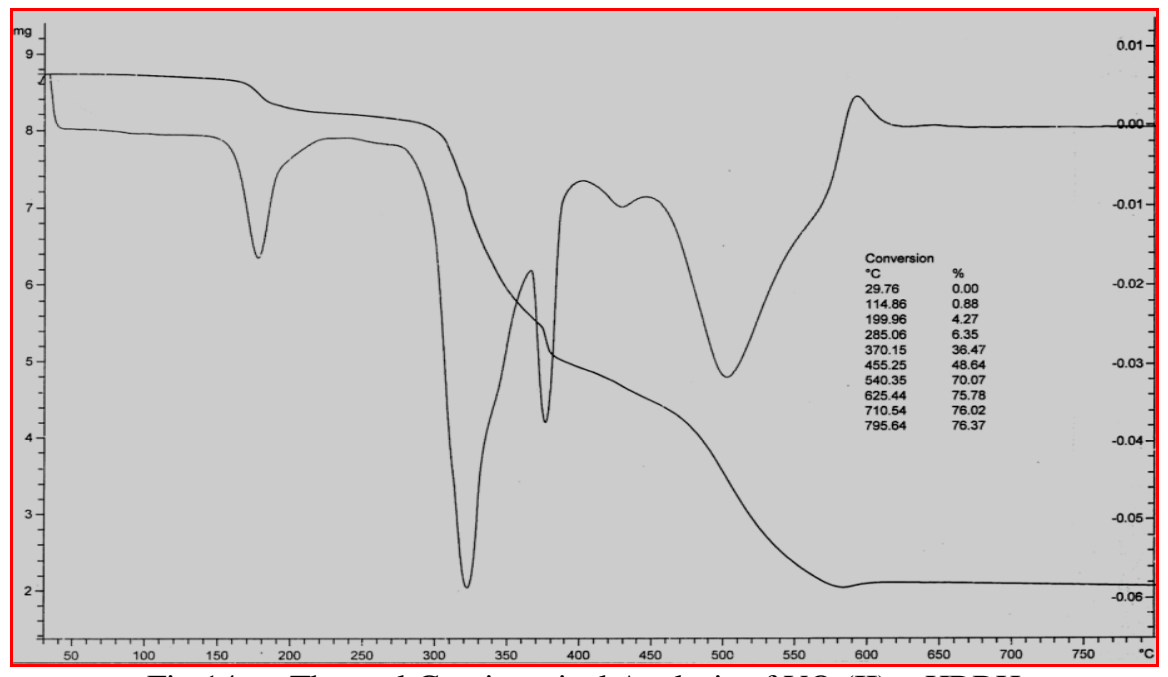

Fig.14 Thermal Gravimetrical Analysis of VO (II) - HBBH 


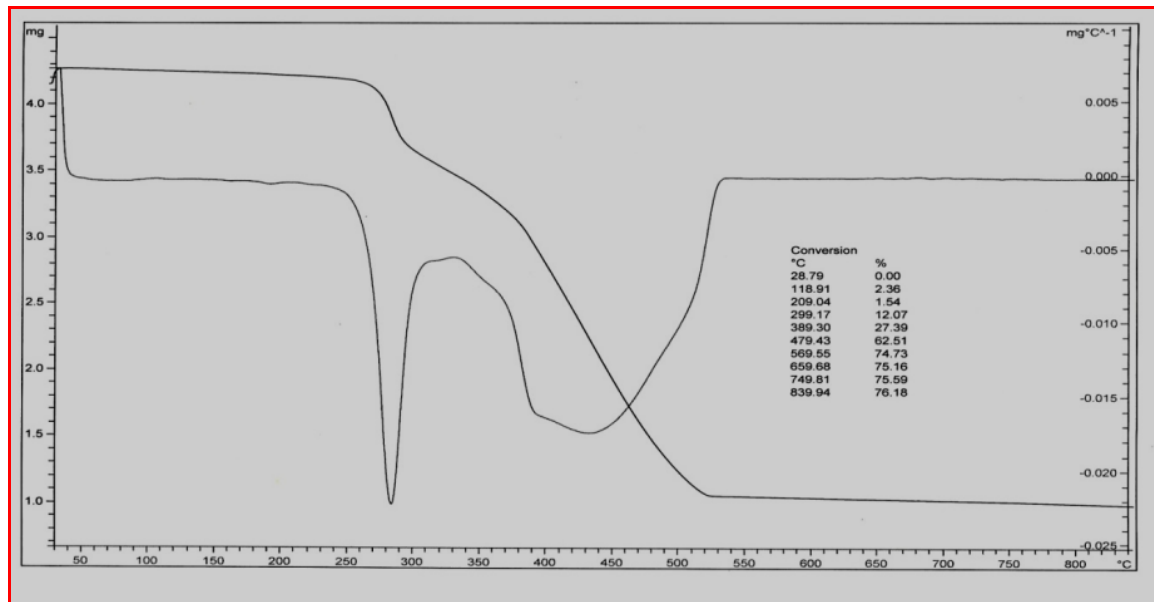

Fig.15 Thermal Gravimetrical Analysis of Mn (II) - HBBH

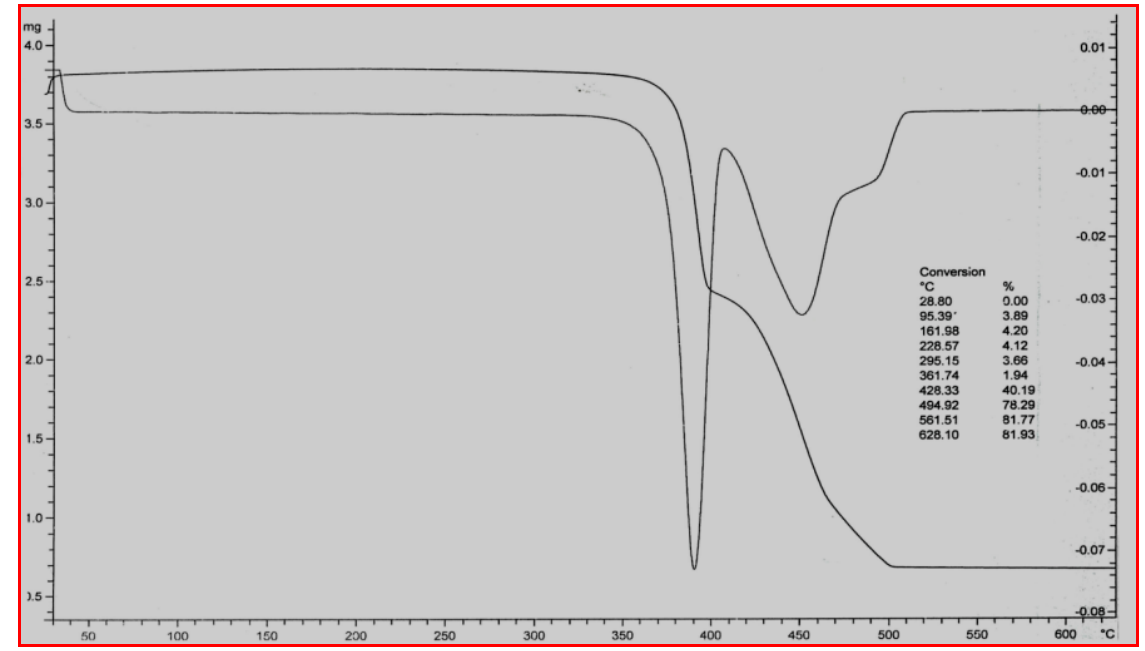

Fig.16 Thermal Gravimetrical Analysis of Co (II) - HBBH

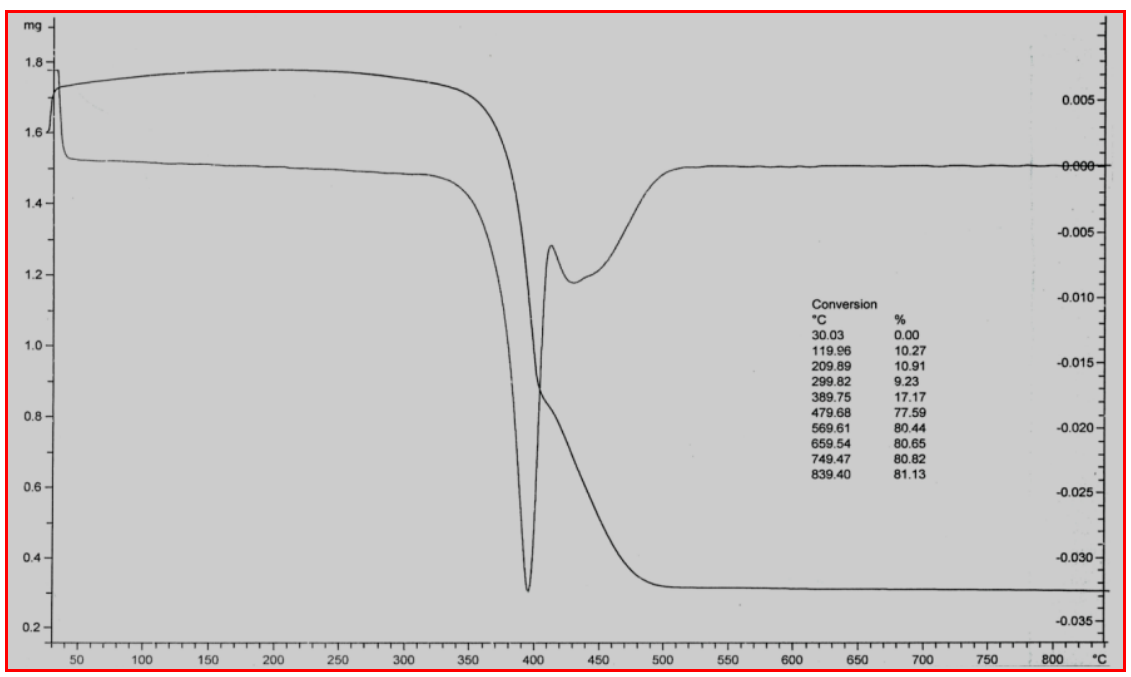

Fig.17 Thermal Gravimetrical Analysis of Ni (II)-HBBH 


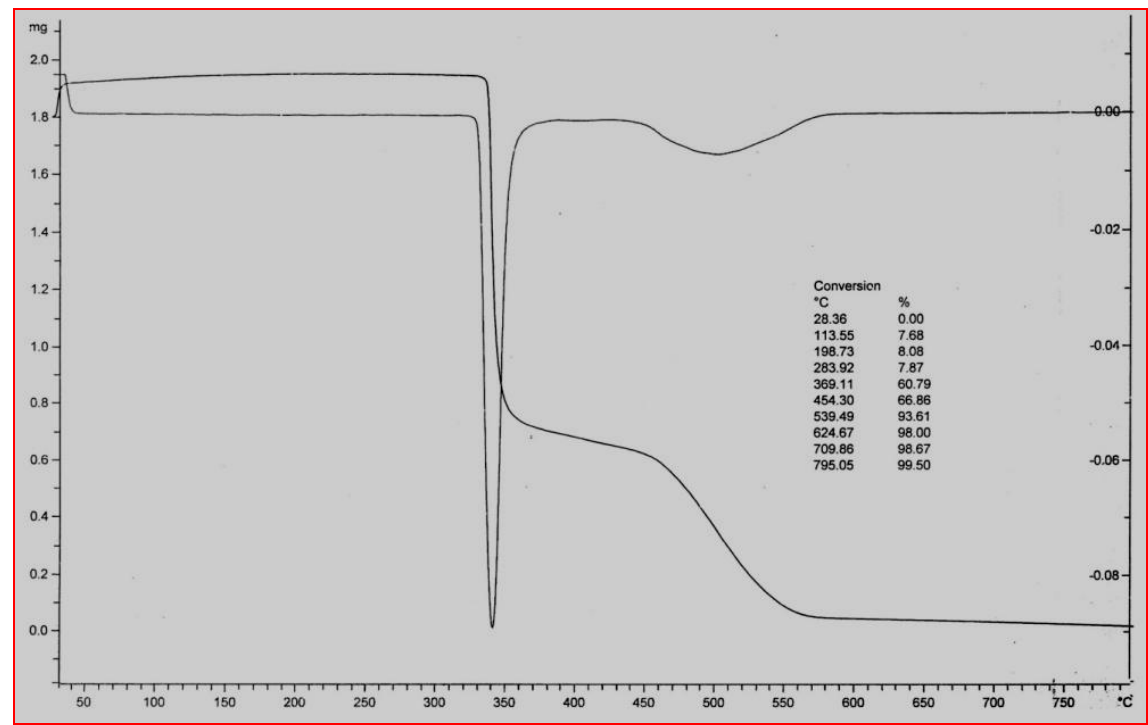

Fig.18 Thermal Gravimetrical Analysis of $\mathrm{Cu}$ (II) - $\mathrm{HBBH}$

The spectral data and Thermal studies ${ }^{15-17}$ supported the composition of VO (II) $-\mathrm{HBBH}$ as 1:1 "Fig. 19", Mn (II) and $\mathrm{Cu}$ (II)-HBBH complexes as 1:1 with coordinated water molecules "Fig. 20" and Ni (II) and Co (II)-HBBH complexes as 1:2 "Fig. 21".

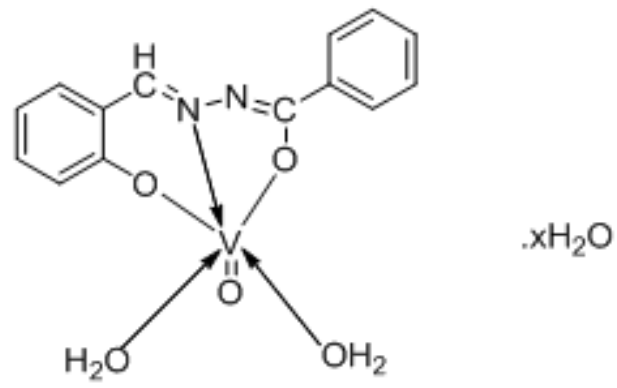

Fig.19 Tentative structure of VO (II)-HBBH complex<smiles></smiles>

Fig.20 Tentative structure of $\mathrm{M}$ (II)-HBBH complex [M(II) $=\mathrm{Cu}$ (II) or $\mathrm{Mn}$ (II)] 
<smiles>[Y14]OC(=O)NN=Cc1ccccc1OC</smiles>

Fig.21 Tentative structure of $\mathrm{M}$ (II)-HBBH complexes [M(II) $=\mathrm{Ni}(\mathrm{II})$ or $\mathrm{Co}(\mathrm{II})]$

\section{Biological activity}

The Biological activity of $\mathrm{Cu}(\mathrm{II})-\mathrm{HBBH}$ complex is studied against gram negative (Escherichis coli) bacteria and the fungal strain Candida albicans.

\subsection{Preparation and Standardization of Stock cultures}

Cultures on receipt were sub cultured in NA/SDA plates and further stored in slanks as stock cultres. For the experiments, stock culture was prepared by inoculating each culture from slants to flask in sterile NB and incubated at $37^{\circ} \mathrm{C}$ for $24 \mathrm{hr}$. The stock culture was adjusted to $0.5 \mathrm{McFarland}$ standard turbidity and used for assay, in case of fungus SDA and SDB are used instead of NA and NB. Sterile NA plates were prepared and $0.1 \mathrm{ml}$ of the inoculums from standardized culture of test organism was prepared uniformly. Wells were prepared by using a sterile borer of diameter $10 \mathrm{~mm}$ and $100 \mu \mathrm{l}$ (To get the final concentration of 1000 and 500 $\mu \mathrm{g} / \mathrm{well})$ of the test substance, standard antibiotic were added in each well separately. A standard antibiotic, ciprofloxacin $(100 \mu \mathrm{l})$ was tested against fungi. The plates were placed at $4^{0} \mathrm{C}$ for $1 \mathrm{~h}$ to allow the diffusion of test solution into the medium and plates were incubated at a temperature optimal for the test organism and for a period of time sufficient for the growth of at least 10 to 15 generations (usually $24 \mathrm{~h}$ at $37^{\circ} \mathrm{C}$ ) for bacteria and (usually $48 \mathrm{~h}$ at room temperature) for fungi. The zone of inhibition of microbial growth around the well was measured in $\mathrm{mm}$.

\subsection{Results}

The Cu(II)-HBBH complex showed inhibitory activity against the fungal strain Candida albicans and gram negative Escherichia coli bacteria. All the results are tabulated in the below table.

Table. I Showing zone of inhibition of bacteria and fungi

\begin{tabular}{|c|c|c|c|c|}
\hline \multirow[t]{3}{*}{ Sample Name } & \multicolumn{2}{|c|}{$\begin{array}{c}\text { Zone of inhibition in mm } \\
\text { bacteria(Escherichia coli -ve) }\end{array}$} & \multicolumn{2}{|c|}{$\begin{array}{r}\begin{array}{r}\text { Zone of inhibition in mm } \\
\text { albicans) }\end{array} \\
\text { fungi (Candida }\end{array}$} \\
\hline & \multicolumn{2}{|c|}{ Concentration } & \multicolumn{2}{|c|}{ Concentration } \\
\hline & $1000 \mu \mathrm{g}$ & $500 \mu \mathrm{g}$ & $1000 \mu \mathrm{g}$ & $500 \mu \mathrm{g}$ \\
\hline $\mathrm{Cu}-\mathrm{HBBH}$ & 16 & 15 & 12 & 11 \\
\hline Standard & \multicolumn{2}{|c|}{$\begin{array}{l}\text { Ciprofloxacin }(10 \mu \mathrm{g}) \\
30\end{array}$} & \multicolumn{2}{|c|}{$\begin{array}{l}\text { Ketoconazole }(20 \mu \mathrm{g}) \\
20\end{array}$} \\
\hline
\end{tabular}



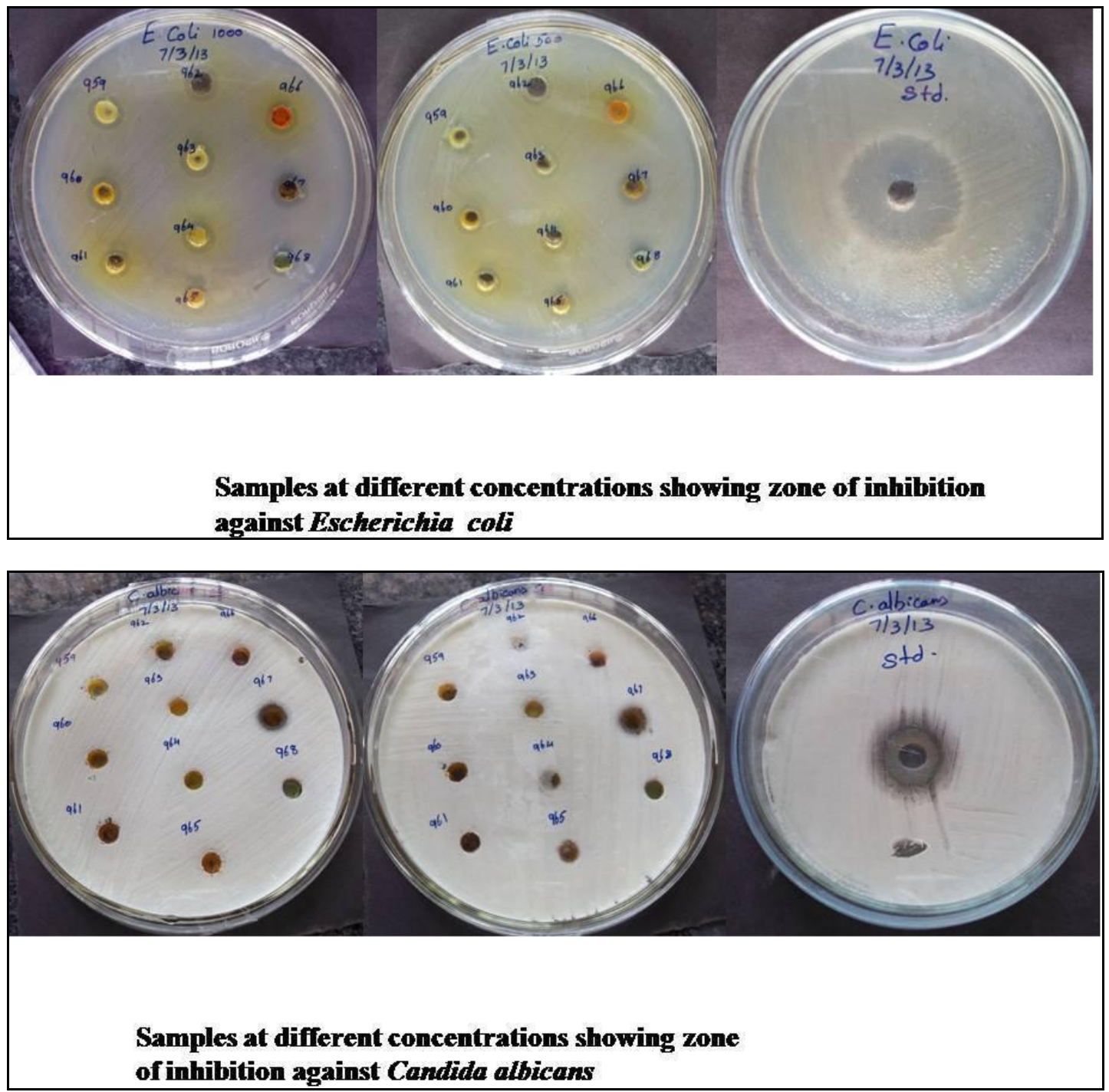

The above results of biological studies proved that the concentration of compounds played a vital role in increasing the degree of inhibition. As the concentration of $\mathrm{Cu}(\mathrm{II})-\mathrm{HBBH}$ complex increases the activity also increased.(Table.I)

\section{Conclusions}

The IR spectra gave information regarding coordinating sites and complex formation. The ${ }^{1} \mathrm{H}-\mathrm{NMR}$ spectra showed evidence for the formation of metal complexes involving phenolic-O, carbonyl-O and azomethine nitrogen in coordination with the metal ion. The mass spectral data provided information regarding metal complex composition. The ESR spectral data gave information about the geometry of the metal complexes. The thermogravimetric analysis gave information regarding the presence of coordinated water molecule. The biological studies proved that the concentration of compounds played a vital role in increasing the degree of inhibition, as the concentration increases the activity also increased. 


\section{References}

[1]. R.L.Dutta, A.K.Sarkar, J.Inorg.Nucl.Chem.43 (1981) 57

[2]. I.S.Ahuza, R.Sriramulu, S.Raghuvir, Indian J.Chem. 19 A (1980) 909

[3]. Rev. Chim. (Bucharest) 1978, 29 (7), 619-22.

[4]. Vogel A.I., A text book of qualitative organic analysis, $3^{\text {rd }}$ ed., (1971) 166

[5]. A.Padmaja, K.Laxmi and Ch.Sarala Devi ${ }^{*}$, J.Indian Chem.Soc., vol.88, Feb.2011

[6]. Ali Ourari, Kamel Ouari et al., Transition Metal Chemistry., 31 (2006) 169-175.

[7]. Tapas Ghosh, Aparesh Roy, Sharmila Bhattacharya and Subhabrata Banerjee, Transition Metal Chemistry., 30 (2005) 419-425.

[8]. Rao C N R 1963 Chemical applications of Infrared spectroscopy (New York: Academic Press) p.265.

[9]. A. K. Panda, D. C. Dash, P. Mishra, and H. Mohanty, Indian Journal of Chemistry A, vol 35, no. 4, pp. 324-327, 1996.

[10]. N. Raman, S. Ravichandran, and C. Thangaraja, Journal of Chemical Sciences India, vol. 116, no. 4, pp. 215-219, 2004

[11]. Nakamoto K 1980 Infrared and Raman spectra of inorganic and coordination compounds (New York: John Wiley \& Sons).

[12]. Mishra AP, Pandey L.R. Synthesis, characterization and solid state structural studies donor Schiff base chelates. Indian Journal of Chemistry A. 1 (2005) 44, p.94-97.

[13]. Maurya MR, Kumar A, Bhat AR, Azam A, Bader C, Rehder D, Inorganic Chemistry., 45 (2006) 3, 1260-1269.

[14]. Mishra AP, Pandey LR, Indian Journal of Chemistry A. 44 (2005) 9, 1800-1805.R. N Raman, J Dhaveethu Raja and A Sakthivel. J.Chem.Sci., vol.119, N0.4, July 2007, pp.303-310.

[15]. Hoi N. P., J. Chem. Soc., (1953) 1358

[16]. Craig J. C., Edger J., Nature (London), 34 (1955) 176.

[17]. Mohan M., Kumar A., Kumar M., Inorg. Chim. Acta, 65 (1987) 136. 